\title{
LOS DERECHOS ECONÓMICOS Y SOCIALES EN LA JURISPRUDENCIA RECIENTE DEL TRIBUNAL EUROPEO DE DERECHOS HUMANOS: UNA SELECCIÓN
}

\author{
CARMEN MORTE GÓMEZ ${ }^{1}$ \\ Letrada Jefa de la División de Difusión de Jurisprudencia \\ Tribunal Europeo de Derechos Humanos
}

\begin{abstract}
SUMARIO
I. ¿Derechos civiles y politicos versus derechos economicos y sociales?. II. Obligaciones positivas de los Estados. III. Prestaciones sociales y derecho de propiedad. IV. ¿Qué ocurre en casos de reducción, denegación o interrupción de prestaciones derivadas de situaciones de crisis económica?. V. El despido por razón de género o de orientación sexual. VI. El derecho a la vivienda. VII. El derecho a la educación. VIII. El derecho a la salud. IX. Conclusiones.
\end{abstract}

\section{I. ¿ DERECHOS CIVILES Y POLÍTICOS VERSUS DERECHOS ECONÓMICOS Y SOCIALES?}

Como es sabido, en el ámbito del Consejo de Europa ${ }^{2}$, el Convenio Europeo de Derechos Humanos, de 4 de noviembre de 1950 (en adelante «el Convenio» o «CEDH») garantiza y protege derechos fundamentalmente civiles y políticos y la Carta Social Europea, de 18 de octubre de $1961^{3}$, derechos fundamentalmente económicos y sociales, según la ya clásica distinción recogida en los Pactos Internacionales, de 16 de diciembre

1 La responsabilidad del presente texto incumbe exclusivamente a su autora, y no representa en modo alguno la posición oficial del Tribunal Europeo de Derechos Humanos o de su Secretaría.

2 Véase, para un estudio detallado de la cuestión, Morte Gómez, C. y Salinas Alcega, S., «Los derechos económicos y sociales en la jurisprudencia del Tribunal Europeo de Derechos Humanos» en EmbId Irujo, A. (dir.), Derechos Económicos y Sociales, Madrid, Iustel, 2009, pp. 359-412.

3 Los órganos de control que recoge la Carta Social Europea son el Comité de Expertos Independientes y el Subcomité del Comité Social Gubernamental (artículos 25 y 27 respectivamente). Respecto del mecanismo de control en este ámbito debe tenerse en cuenta asimismo otros textos como el Protocolo de enmienda a la Carta Social Europea, de 21 de octubre de 1991, el Protocolo adicional a la Carta Social Europea que prevé un sistema de reclamaciones colectivas, de 9 de noviembre de 1995, y la Carta Social Europea (revisada), de 3 de mayo de 1996. España tan sólo es parte del primero de esos tres textos. 
de 1966, sobre derechos civiles y políticos y sobre derechos económicos, sociales y culturales, surgidos en el ámbito de Naciones Unidas. De la garantía de los derechos civiles y políticos se ocupa en el Consejo de Europa el Tribunal Europeo de Derechos Humanos (en adelante, 'el TEDH' o 'el Tribunal'), mientras que los derechos económicos y sociales se protegen mediante un mecanismo no jurisdiccional, el Comité de Derechos Sociales. La principal diferencia entre ambos es, pues, su justiciabilidad, ya que, respecto de los derechos civiles reconocidos por el Convenio y sus Protocolos, el TEDH se expresa mediante Decisiones y Sentencias con carácter obligatorio para los Estados, lo que no es el caso de los informes emitidos en el marco de los procedimientos ante el Comité de Derechos Sociales, ni siquiera de las Decisiones emitidas por el dicho Comité cuando conoce de reclamaciones colectivas sobre derechos económicos y sociales. No se trata, sin embargo, de compartimentos estanco.

El propio Tribunal ha reconocido desde antiguo y, en particular, desde su Sentencia Airey contra Irlanda, de 9 de Octubre de 1979, que muchos de los derechos civiles y políticos enunciados en el Convenio tienen proyecciones de orden económico y social: «(...) el Convenio debe interpretarse a la luz de las condiciones de vida en cada momento (STEDH Marckx c. Bélgica, 13 de Junio de 1979, § 41), y está diseñado para proteger al individuo de forma concreta y efectiva en las áreas de su competencia (...). Si bien el Convenio protege esencialmente derechos civiles y políticos, muchos de ellos tienen implicaciones de naturaleza social y económica. Por ello el Tribunal estima, como tya lo hacía] la Comisión, que el mero hecho de que una interpretación del Convenio pueda extenderse en la esfera de los derechos económicos y sociales no debe ser un factor decisivo contra esa interpretación; no hay una división estanca que separe esa esfera de la del ámbito protegido por el Convenio» ${ }^{4}$.

Varias vías son posibles para que la protección dispensada por el Convenio se extienda a derechos que en principio no están cubiertos por él: por una parte, mediante la inclusión de esos derechos de forma expresa en el sistema del Convenio, como es el caso del trabajo forzado (art. $4 \mathrm{CEDH}$ ), del derecho a crear sindicatos, a sindicarse o a no sindicarse (art. $11 \mathrm{CEDH}$ ) o del derecho a la educación (art. 2 del Protocolo n. ${ }^{\circ} 1$ al $\mathrm{CEDH}$ ); por otra, a través de la aplicación de derechos civiles y políticos en el ámbito laboral (por ejemplo, el derecho a la vida privada del cura católico al que no se renueva su contrato de trabajo por defender el celibato opcional ${ }^{5}$ ); o mediante la integración indirecta que realiza el Tribunal Europeo a través de una interpretación evolutiva, dinámica y efectiva de derechos que sí están contemplados de manera expresa en el Convenio, «instrumento vivo» ${ }^{6}$, o a través de los conceptos autónomos desarrollados en su jurisprudencia («domicilio», «propiedad», etc.). Tal es el caso, por ejemplo, de los derechos de los extranjeros, no protegidos expresamente por el Convenio, que no les concede el derecho, como tal, a no ser expulsados o extraditados ${ }^{7}$ o de las pensiones, que se incluyen en el concepto de «propiedad» del artículo 1 del Protocolo n. ${ }^{\circ} 1$. La

4 Par. 26.

5 STEDH de Gran Sala de 12 de Junio de 2014. Fernández Martínez c. España

6 STEDH de 25 de Abril de 1978. Tyrer c. Reino Unido, § 31.

7 De esta misma autora, «La jurisprudencia del Tribunal Europeo de Derechos Humanos en materia de extranjeros», en Estudios sobre Derecho de extranjería, pp. 191-207. Instituto de Derecho Público, Universidad Rey Juan Carlos, Madrid 2005. 
importancia de la protección de los derechos económicos y sociales y su conexión con los derechos que, como tales, sí están consagrados en el Convenio, han llevado al Tribunal a examinar casos en los que están en juego algunos de esos derechos, «transformándolos» en derechos civiles con dimensión social, o bien mediante una interpretación evolutiva y abierta, como se ha indicado, «llenando de contenido» los derechos incluidos en el Convenio de 1950 y sus Protocolos adicionales para adaptarlos a las condiciones de vida actuales. Otra posibilidad de dar cabida a los derechos sociales en la Jurisprudencia del TEDH se realiza a través de la doctrina de las obligaciones positivas $^{8}$. Empezaremos por esta última.

\section{OBLIGACIONES POSITIVAS DE LOS ESTADOS}

Los derechos sociales han tenido su entrada en el sistema del Convenio también mediante las obligaciones positivas de los Estados Parte, doctrina acuñada por el propio Tribunal Europeo en su jurisprudencia: en virtud de los principios de interpretación evolutiva y dinámica del Convenio y de interpretación efectiva, ya mencionados, el Tribunal adopta una posición más garantista con el objetivo de brindar mayor protección a los derechos y libertades de las personas sujetas a su jurisdicción, haciendo que los derechos no sean teóricos o ilusorios. La interpretación finalista o teleológica de las obligaciones asumidas por los Estados permite al Tribunal extender el ámbito de aplicación de los derechos del Convenio, que no se limitan solo «a abstenerse de las injerencias arbitrarias de los poderes públicos. A esta obligación negativa pueden, pues, añadirse obligaciones positivas inherentes a un respeto efectivo de la vida privada o familiar (...). Estas pueden implicar la adopción de medidas tendentes a asegurar el respeto de la vida privada», como señaló el Tribunal en su sentencia Marcxk c. Bélgica de 13 de junio de 1979, relativa a la diferencia de trato entre los hijos nacidos dentro y fuera del matrimonio, examinada bajo el ángulo del artículo 8 del Convenio. La vulneración del derecho fundamental tendría entonces su origen en una carencia de tipo material (por ejemplo, en la falta de cuidados médicos a un detenido) o en una laguna legislativa, y surge de la negligencia o la pasividad de las autoridades.

El Tribunal examina si las autoridades nacionales conocían o deberían haber conocido la existencia de un riesgo real e inmediato para el individuo que ponga en grave peligro la efectiva vigencia del derecho en cuestión, y si adoptaron todas las medidas que estaban a su alcance para poner fin a dicha situación y para evitar razonablemente que el riesgo siguiera existiendo.

El reconocimiento de la existencia de obligaciones positivas por parte del Estado conduce a preguntarse sobre la extensión de tales obligaciones cuando está en juego la propia supervivencia del individuo, es decir, si la denegación, o la interrupción, por parte de las autoridades, de prestaciones esenciales (por ejemplo, en materia sanitaria o de vivienda, entre otras) puede suponer la violación de derechos sustantivos ${ }^{9}$. Este aspecto será tratado más adelante.

8 Morte Gómez, C. y Salinas Alcega, S., «Los derechos económicos y sociales ...», op. cit., pp. 359-412.

9 López Guerra, L., "Crisis económica y Derechos humanos », Teoría y realidad Constitucional, n. ${ }^{\circ}$ 36, 2015 , pp. 399-414, 403, 404 . 
La cuestión de las condiciones de trabajo aparece también en la jurisprudencia del Tribunal muy claramente a partir de su Sentencia de 26 de julio de 2005 dictada en el asunto Siliadin c. Francia: la demandante, de nacionalidad togolesa, menor y en situación irregular, vivía en Francia con una familia de alto nivel económico y cultural, ocupándose de las tareas domésticas y del cuidado de los niños, trabajando sin horarios, sin descanso, sin vacaciones y sin remuneración. El Tribunal se apoya en la situación de gran vulnerabilidad en la que se encontraba la demandante para afirmar que, como mínimo, había sido objeto de un trabajo forzado y había estado sometida a una situación de servidumbre. Además de esta conclusión sobre el trabajo forzado contrario al artículo 4 del Convenio como consecuencia de las condiciones de trabajo particularmente duras a las que estaba sometida la demandante, el Tribunal afirma, en lo que ahora nos ocupa, que del citado artículo 4 se derivan necesariamente obligaciones positivas para los Estados que exigen la criminalización y la represión efectiva de todo acto tendente a mantener a una persona en ese tipo de situación ${ }^{10}$.

En su Sentencia de 7 de enero de 2010 dictada en el caso Rantsev c. Chipre y Rusia, el Tribunal concluyó que se había vulnerado también, entre otros, el artículo 4 del Convenio. El caso, que trata de la muerte sospechosa de una mujer rusa de 20 años que había sido contratada en Chipre como artista de cabaret y, en realidad, explotada sexualmente, es importante por varios motivos:

a) Por primera vez el Tribunal considera que el tráfico de seres humanos con fines de explotación sexual constituye una nueva forma de esclavitud que se incluye en el campo de aplicación del artículo 4 del Convenio,

b) establece la obligación positiva de los Estados de proteger a las víctimas (o a las víctimas potenciales) de trata de seres humanos y explotación, introduciendo las medidas legislativas y administrativas necesarias y la adopción de medidas de protección,

c) establece la obligación procesal de investigar los hechos, tanto por parte del Estado de origen como del o de los Estados de tránsito y/o destino.

El TEDH insistió en el incumplimiento por parte de Chipre de su obligación de crear el dispositivo legal y administrativo adecuado para luchar contra el tráfico de personas con fines sexuales, por no haber protegido a la demandante a pesar de que existían motivos suficientes para considerar que su vida corría peligro (peligro que ella misma había denunciado ante la policía chipriota) y condenó igualmente a Rusia porque sus autoridades no habían investigado correctamente cuándo y dónde había sido contratada la Sra. Rantsev, ni quiénes la contrataron y de qué manera.

En su Sentencia de 30 de marzo de 2017 dictada en el caso Chowdury y otros c. Grecia, el Tribunal condenó al Estado demandado por su insuficiente reacción frente a una situación de trata de seres humanos resultante de la explotación de la vulnerabilidad de 42 trabajadores migrantes bangladesíes sin permiso de trabajo ni de residencia, que fueron contratados en Grecia como trabajadores agrícolas temporeros, con la promesa de un salario de 22 euros al día, en condiciones de alojamiento indignas, horarios agotadores y

10 Par. 112 de la Sentencia citada. 
bajo la vigilancia de hombres armados. Se convocaron varias huelgas y se produjo un episodio en el que uno de los guardias disparó contra una centena de trabajadores, hiriendo gravemente a una parte de ellos. Se dictaron penas de prisión contra los empleadores y autores de los disparos, que fueron condenados por lesiones pero no por tráfico de personas, como había solicitado el fiscal. Ante el Tribunal, los demandantes estimaron haber sido víctimas de trabajo forzado y denunciaron la ausencia de reacción por parte de las autoridades ${ }^{11}$.

El TEDH recordó que la noción de tráfico de personas no se limita a la explotación sexual sino que abarca también otro tipo de situaciones que se encuentran recogidas en la definición que de tal término realiza el artículo 4 a) del Convenio del Consejo de Europa sobre la lucha contra la trata de seres humanos, lo cual pone en evidencia la estrecha relación existente entre el trabajo forzado u obligatorio y la trata de seres humanos. El consentimiento del trabajador, que puede verse obligado a aceptar tal situación por necesidad, no basta para excluir la calificación de un trabajo como «forzado». Cuando un empleador abusa de su poder o se aprovecha de la situación de vulnerabilidad de sus empleados para explotarlos, estos últimos no prestan su trabajo de manera voluntaria. Esta cuestión debe ser examinada a la luz de las circunstancias del caso. En el presente caso, el Tribunal estimó que las condiciones de trabajo de los demandantes permitían claramente considerar su situación como constitutiva de trabajo forzado y de trata de seres humanos, tal y como la define el artículo 3 a) del Protocolo adicional al Convenio de las Naciones Unidas contra la criminalidad transnacional organizada (Protocolo de Palermo) y el artículo 4 del Convenio contra la trata del Consejo de Europa de 16 de Mayo de 2005, tal y como es interpretado por el Grupo de expertos sobre la lucha contra la trata de seres humanos (GRETA). El Tribunal concluyó que el Estado demandado no respetó sus obligaciones positivas en la materia: prevenir la situación de trata, proteger a las víctimas, llevar a cabo una investigación efectiva y sancionar a los responsables. GRETA ha indicado recientemente, en su informe anual de 2017, que la explotación laboral aumenta en toda Europa hasta el punto de que, en varios países, «ha superado a la explotación sexual como principal forma de tráfico de personas», siendo el retrato robot de la víctima un hombre que trabaja en la agricultura, la construcción y la pesca. GRETA ha urgido, además, a España, en su informe-país publicado el 20 de junio de 2018 a que «adopte, como cuestión prioritaria» un plan de acción integral que incluya medidas para combatir la explotación laboral.

Estos casos examinados hasta ahora bajo el epígrafe de «obligaciones positivas» corresponden a uno de los escasos derechos claramente «económicos y sociales» reconocidos expresamente en el CEDH, en concreto, en su artículo 4, que prohíbe la esclavitud y los trabajos forzados. Otros ejemplos de obligaciones positivas se abordarán en epígrafes posteriores. Más adelante se expondrá algún otro ejemplo en este sentido.

En otro orden de cosas y para concluir este apartado, se hará referencia a un gravísimo caso de efectos de la crisis económica dentro del marco de las obligaciones positivas del Estado: en el caso Nencheva y otros c. Bulgaria ${ }^{12}$, el Tribunal consideró vulnerado el artículo 2 (derecho a al vida) del Convenio, por el fallecimiento de 15 niños con graves minusvalías psíquicas, por falta de alimentos, calefacción y cuidados de base durante 3 meses del

11 Ver también STEDH de 17 de Enero de 2017 dictada en el caso J. y otros c. Austria, n. ${ }^{\circ}$ 58216/12.

12 STEDH de 18 de Junio de 2013. 
invierno de 1996-1997. El Tribunal entendió que se trataba de personas vulnerables cuya vida había sido puesta en peligro mientras se encontraban bajo la responsabilidad y la asistencia del Estado, plenamente consciente de la situación. Se trataba pues, de una cuestión que afecta no sólo a la condición individual de los demandantes, padres de los niños fallecidos, sino de una cuestión de interés público. Las autoridades nacionales tenían, por tanto, la obligación de adoptar de manera urgente las medidas necesarias para proteger la vida de los niños. Fueron, sin embargo, incapaces de reaccionar, durante meses, a los repetetidos mensajes de alerta de la directora de la institución sobre la situación en la misma o la falta de asistencia médica rápida y apropiada. Debían, además, facilitar las explicaciones sobre las causas de los fallecimientos y las eventuales responsabilidades, mediante un procedimiento penal iniciado de oficio. Dicho procedimiento tardó no obstante dos años en empezar y ocho años en tramitarse, y no tuvo la amplitud necesaria para dilucidar todas las circunstancias del caso, determinar los factores que contribuyeron a los fallecimientos en cuestión ni examinar los errores del sistema y la imposibilidad de reacción rápida y apropiada del mismo frente al riesgo existente para la salud y la vida de los niños, ni para garantizar, por tanto, que tales acontecimientos puedan repetirse.

\section{PRESTACIONES SOCIALES Y DERECHO DE PROPIEDAD}

En la evolución jurisprudencial a la que se ha hecho referencia, el Tribunal ha procedido a una interpretación abierta y extensiva de algunas disposiciones que han permitido dar cabida a situaciones de marcado carácter social y, en particular, del artículo 1 del Protocolo n. ${ }^{\circ} 1$, que protege el derecho de todos «al respeto de sus bienes» y que consagra la garantía de la propiedad.

La cuestión de saber si los derechos a una pensión de jubilación o de viudedad están cubiertos por la noción de «bien» del artículo 1 del Protocolo $\mathrm{n}^{\circ} 1$ ha sido examinada por el Tribunal normalmente en supuestos en los que existía discriminación (por razón de género, de nacionalidad, etc.) en la atribución de este tipo de pensiones. Se combinan en este caso la creación de conceptos autónomos por parte de la jurisprudencia del TEDH con el ámbito de aplicación del principio de no discriminación. Es el caso de la Sentencia de 11 de junio de 2002 dictada en el asunto Willis c. Reino Unido, en la que la negativa de las autoridades a conceder al demandante, que había dejado de trabajar para ocuparse de su esposa enferma y de los hijos comunes, una prestación por viudedad y una prestación de «madre viuda» tras el fallecimiento de su esposa, que había trabajado y cotizado toda su vida a la seguridad social y había sido el principal sustento de la familia, fue considerada como una vulneración del artículo 14 del Convenio combinado con el 1 del Protocolo n. ${ }^{\circ} 1^{13}$.

El Tribunal ha declarado igualmente que un trato diferente en el cálculo del importe del derecho a una pensión entre nacionales y no nacionales (entre ciudadanos letones y «residentes no ciudadanos» de origen ruso) constituye una violación del artículo 14 del Convenio, puesto que esa discriminación, basada en la nacionalidad, afectaba a un derecho reconocido en el artículo 1 del Protocolo n. ${ }^{\circ} 1^{14}$.

13 Par. 36.

14 STEDH de Gran Sala de 18 de Febrero de 2009 dictada en el caso Andrejeva c. Letonia. 
En este contexto puede también mencionarse la Sentencia de 30 de septiembre de 2003, en el asunto Koua Poirrez c. Francia, en la que el Tribunal examina la negativa del Estado demandado a conceder al demandante una prestación por minusvalía, ya que dichas prestaciones estaban limitadas por ley a ciudadanos franceses. Para el Tribunal, la diferencia de trato en cuanto a la concesión de prestaciones sociales entre los ciudadanos franceses, o de países que hubieran firmado una convención de reciprocidad, y los otros extranjeros, no descansa en ninguna justificación objetiva y razonable. Considera incluso el TEDH que, aunque Francia no estuviera obligada en el momento de los hechos por acuerdos de reciprocidad con Costa de Marfil, Estado de la nacionalidad del demandante, se había comprometido, al ratificar el Convenio Europeo de Derechos Humanos, a reconocer a toda persona sometida a su jurisdicción, lo cual era el caso del demandante sin ninguna duda, los derechos y libertades reconocidos en el Título I del Convenio ${ }^{15}$ (artículo 1 del Convenio). El Tribunal tuvo en cuenta que el demandante, que no tenia nacionalidad francesa, había sido sin embargo, adoptado por un ciudadano francés, residía en Francia y era titular de un carné de invalidez expedido por las autoridades francesas. Por todo ello concluyó el Tribunal que la diferencia de trato no estaba justificada.

Un caso de diferencia de trato en contexto de pensiones de viudedad fue examinado por el Tribunal en la Sentencia Muñoz Díaz contra España, de 8 de Diciembre de 2009, en la que la existencia de las condiciones necesarias para la obtención de dicha pensión se relacionaba con la presunción de buena fe asumida en el matrimonio religioso (católico) y la ausencia de tal presunción en el matrimonio contraído por el rito propio de la cultura gitana (no reconocido civilmente). El caso trataba sobre la negativa de las autoridades a reconocer la validez de un matrimonio gitano a los efectos de la atribución de una pensión de viudedad. Cuando la Sra. Muñoz Díaz se casó en 1971 por el rito gitano, el único matrimonio válido, salvo apostasía, era el matrimonio canónico de la Iglesia católica. Aunque tras la entrada en vigor de la Constitución del 1978 la demandante habría podido casarse civilmente, el Tribunal consideró que, para ella, el matrimonio contraído por el rito gitano producía los mismos efectos que el matrimonio civil. Para apreciar su buena fe, el Tribunal tuvo en cuenta la pertenencia de la demandante a una comunidad en el seno de la cual la validez del matrimonio contraído según sus propios ritos y tradiciones nunca se había puesto en duda, ni dicho matrimonio se había considerado contrario al orden público por las autoridades nacionales. También tomó nota de la existencia de un consenso internacional entre los Estados miembros del Consejo de Europa en cuanto al reconocimiento de las necesidades particulares de las minorías y la obligación de proteger su seguridad, su identidad y su modo de vida. La firme convicción de la Sra. Muñoz Díaz de su condición de mujer casada se vio indudablemente reforzada, en el caso concreto, por el hecho de que las autoridades le habían reconocido la calidad de esposa de M.D. y de madre de familia numerosa. Esto había creado en la demandante el convencimiento legítimo de ser la esposa de M.D. y de formar con él una pareja casada reconocida. Tras el fallecimiento de M.D. es, pues, natural, que la demandante hubiera alimentado la esperanza de obtener una pensión de viudedad, que además le fue efectivamente reconocida por el juez de lo social en primera instancia. Por lo tanto, el no reconocimiento de la calidad de cónyuge a la demandante a los fines de la obtención de la pensión de

15 Par. 49 de la Sentencia citada. 
viudedad contradice el reconocimiento previo de esta calidad por las autoridades, omitiendo así tomar en consideración las especificidades sociales y culturales de la demandante para apreciar su buena fe. A la vista de las circunstancias propias del presente caso y teniendo en cuenta que el Estado había atribuido a la demandante y a su familia un libro de familia, que les había reconocido la condición de familia numerosa, que la interesada y sus seis hijos tenían derecho a la asistencia sanitaria y que su esposo, también de etnia gitana, había cotizado a la seguridad social durante más de diecinueve años, el TEDH concluye que es desproporcionado no reconocer los efectos del matrimonio gitano en materia de cobro de la pensión de viudedad en el caso concreto.

Resulta también de relevancia a los efectos comentados la Sentencia dictada en el caso Manzanas Martín c. España, de 3 de Abril de 2012, por la que el Tribunal condenó al Estado español por vulneración del artículo 14 del Convenio combinado con el artículo 1 del Protocolo n. ${ }^{\circ} 1$ en virtud de la diferencia de trato existente en materia de pensiones de jubilación entre ministros de diferentes religiones a la hora de tomar en consideración los años de actividad pastoral en el calculo de la pensión de jubilación de los sacerdotes católicos y de los pastores evangélicos. En efecto, los sacerdotes católicos fueron incluidos en el régimen de la Seguridad Social 22 años antes que los pastores evangélicos, a quienes no se les permitía integrar los años de actividad pastoral anteriores a su afiliación al régimen de la Seguridad Social, para así poder completar el período mínimo de cotización exigido para tener derecho a pensión. El juez de lo social consideró que esta diferencia de trato era contraria al carácter aconfesional del Estado español, y le dio la razón al demandante en la primera instancia. La sentencia fue, no obstante, revocada. A pesar del margen de apreciación con el que cuentan los Estados en la materia, el TEDH estimó que el Gobierno no había justificado las razones de tal diferencia de trato entre situaciones similares, teniendo en cuenta que la misma estaba fundada exclusivamente en el tipo de confesión religiosa a la que el demandante pertenecía ${ }^{16}$.

Desde un ángulo distinto al derecho de propiedad la jurisprudencia del TEDH protege también los derechos procesales en el marco de los procedimientos laborales, a los que considera «contestaciones en materia civil» incluídas — y protegidas- por el artículo 6 del Convenio (derecho a un juicio justo). Se garantiza, en efecto, entre otros, el derecho a la ejecución correcta y sin dilaciones de las sentencias dictadas por los tribunales de la jurisdicción social. En la Sentencia García Mateos c. España, de 19 de Febrero de 2013, el TEDH condenó al Estado español por vulneración del derecho a un juicio justo, en su vertiente del derecho a la ejecución de sentencias firmes. El caso trataba de la negativa de una empresa a adecuar los horarios laborales de una empleada para el cuidado de su hijo, impidiendo o, al menos, dificultando, la conciliación de su vida profesional con su vida familiar. La condena intervino porque, a pesar de que el derecho a esa adecuación de horarios le había sido reconocido a la demandante por el Tribunal Constitucional, tal reconocimiento no fue, sin embargo, efectivo, ni por parte de los tribunales laborales ordinarios

16 Ver también, STEDH de Gran Sala dictada en el caso Fábián c. Hungría, de 5 de Septiembre de 2017, sobre diferencia de trato con respecto a las pensiones de jubilación entre trabajadores del sector público y del sector privado (no vulneración) o Decisión (de inadmisión) en el caso Gellérthegyi y Balla, y Balláné Gál c. Hungría, de 6 de Marzo de 2018, sobre diferencia de trato con respecto a las pensiones de jubilación entre trabajadores del sector público (funcionarios) y trabajadores en régimen laboral en el sector público. Ver igualmente STEDH de Gran Sala de 6 de Julio de 2005 dictada en el caso Stec y otros c. Reino Unido, sobre diferencia de trato entre hombres y mujeres ante prestaciones por accidente de trabajo. 
ni por parte del alto tribunal. Este último, en un segundo procedimiento de amparo, que él mismo decidió abordar como incidente de ejecución de su primera Sentencia, volvió a dar la razón a la demandante. Sin embargo, y puesto que su hijo ya había cumplido la edad máxima legalmente establecida para poder disfrutar de la adecuación de horarios laborales, la demandante solicitaba entonces una indemnización. El auto dictado por el Tribunal Constitucional consideró que su primera sentencia había sido ejecutada inadecuadamente, declaró nula también la segunda sentencia del juez de lo social pero estimó, sin embargo, innecesaria la retroacción del procedimiento debido a la edad del menor, entendiendo que la fijación de una indemnización alternativa no le era posible en aplicación del artículo 92 LOTC $^{17}$.

\section{IV. ¿QUÉ OCURRE EN CASOS DE REDUCCIÓN, DENEGACIÓN O INTERRUPCIÓN DE PRESTACIONES DERIVADAS DE SITUACIONES DE CRISIS ECONÓMICA?}

En algunos supuestos muy específicos respecto de personas totalmente dependientes de la acción de los poderes públicos, como pueden ser, por ejemplo, los reclusos en establecimientos penitenciarios, pueden darse lugar a vulneraciones de derechos sustantivos (Rotaru contra Moldavia, STEDH de 15 de Febrero de 2011). El Tribunal debe examinar estos casos desde el punto de vista de los derechos civiles y políticos protegidos por el Convenio, pronunciándose sobre las consecuencias humanas de la crisis económica, respetando el principio de subsidiariedad, de proporcionalidad y de no discriminación así como el margen de apreciación de los Estados, preservando siempre los derechos inderogables, es decir, aquellos que constituyen el núcleo duro de los derechos fundamentales protegidos por el Convenio, entre los que se encuentran, por ejemplo, el derecho a la vida, la prohibición de las torturas y malos tratos o la prohibición de la esclavitud. Si bien el derecho general de una persona a recibir prestaciones necesarias para su supervivencia, como consecuencia de mandatos concretos del Convenio, no aparece reconocido en la jurisprudencia del Tribunal, no cabe, sin embargo, excluir totalmente que ciertos derechos tales como el derecho a la vida, a la integridad física o a la vida familiar puedan aplicarse al ámbito de las prestaciones sociales. Se trata, siempre, de un examen individualizado, casuístico, que analiza la posible vulneración de alguno de los derechos citados y no la existencia o no del derecho, como tal, a una prestación económica determinada.

Un buen ejemplo puede ser el caso Koufaki y Adedy c. Grecia ${ }^{18}$ relativo a la disminución de salarios, pensiones y otras prestaciones sociales en el sector público como consecuencia de las medidas de austeridad adoptadas en 2010-2011, que sigue la jurisprudencia constante según la cual el derecho de propiedad no garantiza un salario o una pensión de un importe determinado. Pero la Decisión es, no obstante, importante, en la medida en que el Tribunal se coloca explícitamente en el contexto «de una crisis excepcional y sin precedentes en la historia reciente de Grecia». El Tribunal afirma que, teniendo en cuenta las circunstancias, el legislador dispone de una «gran latitud» en la materia, de

17 Indirectamente se protege también en este caso el derecho a la maternidad, inherente al derecho de la vida familiar, consagrado en el artículo 8 del Convenio.

18 Decisión de inadmisión de 7 de Mayo de 2013. 
un amplio margen de apreciación. Salvo arbitrariedad o irracionabilidad, la decisión del legislador en un contexto de crisis entra dentro de su margen de apreciación. El juez internacional se autolimita por la invocación del principio de subsidiariedad. Su función no es, pues, hacer política económica ${ }^{19}$.

Otro ejemplo claro de esa amplitud en el margen de apreciación del que disponen las autoridades de los Estados en este ámbito y de la autolimitación del Tribunal lo constituye la Sentencia Mamatas y otros c. Grecia de 21 de Julio de 2016, que trata sobre la imposición de una reducción del valor nominal de ciertas obligaciones sin recabar el consentimiento de sus titulares personas físicas, para disminuir el importe de la deuda pública. Los títulos de los demandantes fueron anulados y sustituidos por nuevos títulos que suponían una pérdida del $53,5 \%$.

El Tribunal entendió que esta aceptación forzosa de los nuevos títulos constituía una injerencia en el derecho de los demandantes al respeto de sus bienes garantizado por el artículo 1 del Protocolo n. ${ }^{\circ} 1$. La injerencia perseguía no obstante un fin de utilidad pública —el mantenimiento de la estabilidad económica y la reestructuración de la deuda- en un momento en el que Grecia atravesaba una grave crisis económica. El Tribunal estimó por ello que los demandantes no habían sufrido una carga especialmente excesiva, teniendo en cuenta en particular el amplio margen de apreciación de los Estados en la materia así como la disminución del valor de los títulos ya afectados por la reducción de la solvencia del Estado, que no habría probablemente podido hacer frente a las obligaciones derivadas de las clausulas incluídas en los títulos antiguos antes de la entrada en vigor de la nueva ley. El Tribunal consideró también que la reestructuración de la deuda pública constituía una medida apropiada y necesaria para la reducción de la misma y para evitar la suspensión de pagos del Estado, que la inversión en obligaciones no estaba exenta de riesgos y que los demandantes debían ser conscientes del riesgo de una pérdida de valor eventual de sus títulos, a la vista del déficit y del endeudamiento elevados en Grecia, incluso antes de la crisis de 2009.

Por su parte, en la Decisión P. Plaisier B.V. y otros c. Holanda, de 7 de Diciembre de 2017, sobre medidas presupuestarias de austeridad y su compatibilidad con el Protocolo $\mathrm{n} .{ }^{\circ} 1$, el Tribunal recapitula de manera detallada los casos examinados relativos a este tipo de medidas. Globalmente, entiende el TEDH, las medidas adoptadas en el Estado demandado no sobrepasaban los límites del margen de apreciación permitido en materia fiscal, y no rompían el equilibrio entre el interés general y la protección de los derechos individuales de las empresas demandantes. El Tribunal recuerda que ya había aceptado medidas de austeridad adoptadas por otros países — como los recortes en salarios del sector público (Decisión Koufaki y Adedy c. Grecia, precitada) y en las restricciones impuestas a los titulares de bonos del Gobierno griego (Sentencia Mamatas y otros $c$. Grecia, precitada)— que eran mucho más dramáticas en sus efectos sobre los individuos que la sobrecarga impositiva en cuestión en el presente caso, y que las del Estado demandado se inscribían también dentro del objetivo perseguido de respetar las reglas presupuestarias fijadas por la Unión Europea.

El Tribunal concluyó sin embargo que se había vulnerado el art. 1 del Protocolo n. ${ }^{\circ}$ 1 en un caso de imposición exageradamente elevada del importe de una indemnización

19 Ver también STEDH de 8 de octubre de 2013 dictada en el caso Da Conceiçã Mateus et Santos Januário c. Portugal y Decisión de 15 de Octubre de 2013 dictada en el caso Savickas c. Lituania. 
por despido. El caso trataba de una funcionaria despedida el 27 de mayo de 2011, con efectos al 28 de Julio de 2011, con derecho a indemnización correspondiente al importe de sus vacaciones no utilizadas y a 8 meses de sueldo. Estas sumas fueron gravadas en virtud de una ley que entró en vigor el 14 de Mayo de 2011 y que aumentaba el tipo impositivo de las indemnizaciones por despido en el sector público. La demandante tuvo que soportar una carga impositiva de alrededor de un $52 \%$ sobre su indemnización por despido, mientras que el tipo impositivo general sobre la renta era de un $16 \%$ en el periodo en cuestión. Se trata de la Sentencia de 14 de mayo de 2013 dictada en el caso N.K.M. c. Hungría.

Para el Tribunal, la indemnización por despido es un interés esencial que «ya había sido ganado o constituía un crédito seguro», por lo que se trataba de un «bien» en el sentido del artículo 1 del Protocolo $n .^{\circ} 1$. La medida impositiva tenía por objeto proteger las finanzas públicas contra el gasto excesivo. Pero aunque los Estados tienen un amplio margen de apreciación en materia fiscal que puede ajustar, limitar o reducir el importe de la indemnización por despido, el tipo impositivo del $52 \%$ aplicado a la demandante excedía considerablemente el tipo aplicable a las demás rentas y, en particular, a esas indemnizaciones en el sector privado. El Tribunal considera que la demandante tuvo que soportar una carga excesiva y desproporcionada. Además, el impuesto fue retenido directamente por el empleador, sin evaluación personalizada de la situación de la demandante, y se aplicó sobre ingresos obtenidos en actividades anteriores al año fiscal en cuestión. Una imposición a un tipo mucho más elevado que el que estaba en vigor en el momento en el que la renta se generó puede considerarse como una limitación no razonable del derecho de propiedad protegido por el artículo 1 del Protocolo ${ }^{\circ}{ }^{\circ}$, por lo que la medida en cuestión se consideró desproporcionada con respecto al objetivo legítimo perseguido.

\section{EL DESPIDO POR RAZÓN DE GÉNERO O DE ORIENTACIÓN SEXUAL, O POR MOTIVOS RELIGIOSOS}

Las Sentencias de 27 de Septiembre de 1999 dictadas en los casos Lustig-Prean y Beckett c. Reino Unido y Smith y Grady c. Reino Unido, y de 22 de Octubre de 2002, Perkins y R. c. Reino Unido y Beck, Copp y Bazaley c. Reino Unido, trataban sobre el despido de miembros de las fuerzas armadas del Reino Unido por el único motivo de su orientación sexual, en virtud de una reglamentación del ministerio de Defensa. Los demandantes alegaban que la investigación sobre su sexualidad, y su despido en virtud de la prohibición total de que los homosexuales prestaran sus servicios en el ejército vulneraban sus derechos a la vida privada y a la prohibición de discriminación. El Tribunal consideró que las medidas adoptadas frente a los demandantes habían constituido injerencias especialmente graves de los derechos invocados y sin razones convincentes ni sólidas.

Por su parte, la Sentencia Emel Boyraz c. Turquía de 2 de Diciembre de 2014 expone un caso de despido en el sector publico por el que una empresa de electricidad despide a la demandante exclusivamente por razón de género, a pesar de llevar trabajando casi tres años en dicha empresa como agente de seguridad, por no ser un hombre y no haber, por tanto, prestado el servicio militar. El Tribunal condenó a Turquía por vulneración del artículo 14 en relación con el artículo 8 por entender que el simple hecho de que los agentes de seguridad deban trabajar por la noche en zonas rurales y utilizar armas de 
fuego y su fuerza física en caso de agresión no justifica, por sí solo, una diferencia de trato entre hombres y mujeres. Por otra parte, los motivos del despido de la demandante no se relacionaban con una presunta incapacidad para asumir tales riesgos o responsabilidades, ya que nada indicaba que no hubiera sido capaz de asumirlos en el desempeño de sus funciones, sino con la decisión de las jurisdicciones administrativas turcas, que no habían no obstante justificado la exigencia de que solo agentes masculinos pudieran ser empleados como agentes de seguridad por la agencia pública de electricidad.

En otro orden de cosas el Tribunal ha examinado también diversas situaciones relacionadas con la religión y con los símbolos religiosos que han dado lugar a despidos o que han tenido consecuencias disciplinarias. Valga por todas, como ejemplo, la Sentencia de 26 de Noviembre de 2015 dictada en el caso Ebrabimian c. Francia, sobre no renovación de un contrato de empleada en un hospital por la negativa de la demandante a retirar el pañuelo islámico que cubría su cabeza. El Tribunal consideró que la restricción en el ejercicio de la libertad religiosa de la demandante estaba justificada y perseguía el objetivo legítimo de la protección de los derechos y libertades de los demás. En cuanto a la necesidad de la medida, el Tribunal observó que la administración había indicado a la demandante las razones de su decisión en el marco del servicio psiquiátrico de un hospital. Por otra parte, y según habían determinado las jurisdicciones internas, la exigencia de neutralidad impuesta a la demandante era aún más importante por sus contactos con los pacientes que se encontraban en estado de fragilidad o de dependencia. El Tribunal tuvo en cuenta el principio de laicidad-neutralidad del estado imperante en Francia y recordó que no le correspondía apreciar o evaluar tal modelo en sí mismo, incumbiendo al juez administrativo la supervisión del carácter desproporcionado o no de la injerencia en el derecho a la libertad de conciencia de los agentes públicos frente a la invocación de neutralidad del Estado ${ }^{20}$.

\section{EL DERECHO A LA VIVIENDA}

El derecho a la vivienda, en relación con el derecho al respeto de la vida privada y familiar o con la prohibición de malos tratos, por ejemplo, en casos en los que están en juego minorías o grupos vulnerables, como los gitanos o los niños ha sido también ampliamente examinado por el Tribunal: en la Sentencia Yordanova c. Bulgaria, de 24 de Abril de 2012, los demandantes, de etnia gitana, se quejaban de la orden del ayuntamiento de desalojar sus viviendas, en las que había residido ilegalmente durante muchos años, pero bajo un régimen de tolerancia de facto. El Tribunal estimó que el derecho de esas personas a la vida privada se había visto vulnerado, por la falta de ponderación de las autoridades de la necesidad del desalojo, a la vista de la posición especialmente vulnerable de los miembros del colectivo gitano y de la falta de previsión para su realojo en condiciones aceptables ${ }^{21}$.

20 Para un repaso de los principios aplicables en cuanto a la prohibición de llevar ropa que oculte el rostro (burka, niqab) en el espacio público, puede consultarse la Sentencia de Gran Sala de 1 de Julio de 2014 dictada en el caso S.A.S. (Demanda n. ${ }^{\circ} 43835 / 11$ ).

21 Para evitar repeticiones, me remito a López Guerra, L., «Crisis económica y Derechos humanos », op. cit., pp. 406-408 en cuanto al análisis de este derecho y a su aplicación a personas vulnerables y, en particular, en cuanto 
En Bagdonavicius y otros c. Rusia, Sentencia de 11 de Octubre de 2016, el Tribunal concluyó igualmente que se había vulnerado el derecho al respeto de la vida privada y familiar en un caso de demolición de viviendas y evicción forzosa de los demandantes, de etnia gitana. Estimó que no se había realizado un examen de proporcionalidad en el marco de los procedimientos relativos a la demolición y que las autoridades nacionales no habían consultado con los interesados sobre las posibilidades de realojo en función de sus necesidades y con carácter previo a su expulsión forzosa.

Algunos casos relativos al derecho a la vivienda se han examinado por el Tribunal desde disposiciones diferentes a las ya citadas, que parecerían en principio menos evidentes para albergar estas situaciones. Mediante la interpretación evolutiva del Convenio y sus Protocolos, la jurisprudencia del TEDH permite el examen de casos desde diferentes ángulos. Valga como ejemplo la Sentencia de Gran Sala de 6 de Noviembre de 2017 dictada en el caso Garib c. Holanda, en el que la demandante, beneficiaria de una prestación social, se quejaba de las restricciones de residencia impuestas en un barrio de Rotterdam que hasta entonces se caracterizaba por una alta tasa de desempleo, y entendía que dichas restricciones para seguir residiendo en dicho barrio (entre otras, tener un determinado nivel de renta) le impedían elegir libremente su lugar de residencia (aunque el propietario de su vivienda de alquiler le había propuesto otra en el mismo barrio). El Tribunal concluyó que la no concesión de la autorización de residencia que le habría permitido residir en la vivienda de su elección en el barrio en cuestión no tuvo consecuencias que pudieran asimilarse a una exigencia desproporcionada, por lo que no se vulneró el artículo 2 del Protocolo n. ${ }^{\circ} 4$ (libertad de circulación / derecho a elegir libremente su residencia).

También se han examinado estas cuestiones relativas a la vivienda desde el prisma de la (no) ejecución de sentencias firmes. En la Sentencia Tchokontio Happi c. Francia, de 9 de Abril de 2015, por ejemplo, el Tribunal entendió vulnerado el artículo 6 del Convenio por la inejecución de una sentencia firme sobre realojo en un caso en el que las autoridades habían asegurado a la demandante la prioridad de realojo porque su vivienda social era insalubre. En la Sentencia piloto Gerasimov c. Rusia, de 1 de Julio de 2014, por su parte, el Tribunal sacó a la luz la existencia de un problema sistémico de falta de adecuación entre la obligación social del Estado de proporcionar una vivienda o prestaciones en especie a ciertas personas, reconocida por sentencia firme, y la incapacidad de las autoridades de respetar tal obligación, en la práctica, mediante la invocación frecuente de la falta de medios.

\section{EL DERECHO A LA EDUCACIÓN}

El derecho a la educación, otro de los escasos derechos puramente económicos y sociales reconocidos por el Convenio y sus Protocolos, del que derivan obligaciones positivas para los Estados consistentes en el deber de adoptar las medidas necesarias para poner en práctica un sistema de educación primaria y secundaria gratuito, se garantiza por el artículo 2 del Protocolo n. ${ }^{\circ} 1$ al Convenio. Los Estados no tienen la obligación de

a los casos contra España examinados en ese contexto. 
organizar un sistema de educación y de enseñanza determinado, o de privilegiar un modelo didáctico u otro, o de establecer programas escolares de un contenido particular. Este margen de apreciación debe garantizar, sin embargo, que el acceso a la educación no sea discriminatorio y que se respeten las convicciones religiosas y filosóficas de los padres, ya sea asegurando una enseñanza pluralista o bien garantizando la posibilidad para los alumnos de ser dispensados de los cursos que herirían la sensibilidad de sus padres. Estas cuestiones se examinaron en la Sentencia de Gran Sala de 13 de Noviembre de 2007 dictada en el asunto D.H. y otros c. República Checa, relativa a la aplicación a niños gitanos de la legislación relativa a escuelas especiales para niños con minusvalía mental, tras la realización de un test de orientación. El Tribunal concluye que se había vulnerado el artículo 2 del Protocolo n. ${ }^{\circ} 1$ porque, aunque la legislación citada no tenía en un principio intención discriminatoria, su aplicación daba lugar a un número desproporcionadamente alto de orientaciones equivocadas en la educación de los niños gitanos. El Tribunal recuerda además que las diferencias de trato fundadas en la raza, el color o el origen étnico deben ser interpretadas lo más estrictamente posible, añadiendo que las mismas son discriminatorias si falta una justificación objetiva y razonable, es decir si no persiguen un fin legítimo, o si no existe una relación razonable de proporcionalidad entre los medios empleados y el fin perseguido.

En su Sentencia dictada en el caso Enver Şahin c. Turquía, de 30 de Enero de 2018, el Tribunal concluyó que se había vulnerado el artículo 2 del Protocolo n. ${ }^{\circ}$ 1, (en la misma línea), por ausencia de evaluación concreta e individualizada de las necesidades de un estudiante minusválido para garantizarle la accesibilidad a los locales de la universidad. El Tribunal consideró que el Estado demandado no demostró que las autoridades nacionales hubieran reaccionado con la diligencia requerida para que el demandante pudiera continuar su educación en condiciones de igualdad con los demás estudiantes. La ayuda propuesta por el rectorado no tuvo en cuenta las necesidades reales del demandante ni consideró adecuadamente los efectos potenciales sobre su seguridad, su dignidad y su autonomía. Las jurisdicciones nacionales no verificaron, según concluyó el Tribunal, si existía un justo equilibrio entre los intereses concurrentes del interesado, es decir, sus necesidades educativas, y los de la sociedad en su conjunto.

La Sentencia dictada en el caso Döner y otros c. Turquia, de 7 de Marzo de 2017, examina desde el punto de vista de la libertad de expresión, las reclamaciones de los demandantes, padres detenidos y perseguidos penalmente por presunta complicidad con una organización armada ilegal (el PKK) y juzgados por un tribunal de seguridad, por reivindicar para sus hijos menores el derecho a la enseñanza en idioma kurdo. Finalmente fueron absueltos. El Tribunal consideró que estas medidas constituyen una injerencia en el derecho al respeto de la libertad de expresión de los demandantes que, a pesar de haber sido absueltos, no han visto reconocido ni reparado su derecho. Tales injerencias no eran necesarias en una sociedad democrática. Aunque el Tribunal no subestima las dificultades de la lucha contra el terrorismo, éstas no eximen por sí solas a las autoridades nacionales de respetar sus obligaciones derivadas del artículo 10 del Convenio. El Tribunal tuvo en cuenta:

i) que las demandas sobre la enseñanza en idioma kurdo en los colegios de primaria se presentaron cuando existía un importante debate público sobre los derechos sociales y culturales de los ciudadanos turcos de origen kurdo en Turquía y se trataba, por tanto, de una cuestión de «interés público»; 
ii) las autoridades utilizaron todo su arsenal jurídico de manera casi represiva, en vez de utilizar la vía penal con parsimonia;

iii) ni las opiniones expuestas en las demandas ni la forma en la que se presentaron plantea duda alguna sobre su carácter pacífico, y el hecho de que las peticiones pudieran parcialmente coincidir con los objetivos de una organización armada ilegal no las excluye de la protección del artículo 10;

iv) en el curso del proceso, la ley sobre los idiomas extranjeros en la enseñanza fue modificada, y prevé ahora este tipo de enseñanza en kurdo al menos en la enseñanza privada en un primer momento.

\section{EL DERECHO A LA SALUD}

El derecho a la salud incluye la obligación de los Estados de intervenir para prevenir y eliminar, en la medida de lo posible, todos los riesgos en materia de salud pública, en particular, los ligados al medio ambiente. El Convenio no reconoce en ninguna de sus disposiciones, ni en las de sus Protocolos, derecho alguno al medio ambiente, o a un medio ambiente sano o adecuado, ni siquiera un derecho a un nivel de vida adecuado que asegure la salud y el bienestar, como sí hace el artículo 25 de la Declaración Universal de los Derechos Humanos de 10 de diciembre de 1948. El Tribunal, encargado de la aplicación e interpretación del Convenio, al que siempre define como un instrumento vivo, ha venido protegiendo indirectamente este derecho ligándolo, en particular, con el derecho a la vida privada y familiar y al domicilio, pero también, con el derecho a la vida o el derecho a la propiedad privada. Así, el Tribunal, en su Sentencia de 9 de diciembre de 1994, en el asunto López Ostra c. España, concluía en la vulneración del artículo 8 del Convenio, por las molestias (olores) producidas por una depuradora próxima al domicilio de la demandante. Lo mismo puede decirse de la Sentencia de 16 de noviembre de 2004, en el asunto Moreno Gómez c. España, en la que se invocaba el daño a la salud ocasionado por el alto nivel de ruidos nocturnos.

Más recientemente, el Tribunal ha considerado que existía vulneración del artículo 2 en este contexto, en la Sentencia de 20 de marzo de 2008 dictada en el asunto Budaieva y otros c. Rusia, en el que se examinaba un corrimiento de tierras que provocó la muerte de varios habitantes de la zona. El Tribunal recuerda que los Estados tienen un amplio margen de apreciación para determinar las medidas a adoptar, en el ámbito de sus obligaciones positivas, cuando se trata de hacer frente a situaciones difíciles de carácter social o técnico, e indica que esta consideración cobra todavía más peso cuando se trata de una situación de emergencia relacionada con una catástrofe meteorológica que, como tal, escapa al control humano.

Dentro de este ámbito, merece la pena señalar la sentencia de la Gran Sala de 30 de noviembre de 2004, dictada en el caso Öneryildiz c. Turquía, relativa a un asunto mencionado anteriormente en el que el domicilio del demandante había resultado destruido por la explosión de metano de un basurero junto al cual la vivienda familiar había sido construida ilegalmente, sin permiso. El Tribunal entiende que las autoridades habían tolerado dicha situación durante un cierto número de años, por lo que se había producido un reconocimiento de facto del interés patrimonial que el interesado y su familia tenían 
en relación a su vivienda y a sus bienes muebles, y que existía por tanto un vínculo de causalidad claro entre la negligencia grave de las autoridades y la destrucción de la vivienda del demandante, pudiéndose haber adoptado medidas preventivas para evitar los riesgos medioambientales de los que las autoridades ya habían sido advertidas, y ello a pesar de que los demandantes no eran jurídicamente propietarios de sus viviendas ni del terreno en el que las mismas estaban construidas, y que se encontraban en infracción de la legislación turca.

Otras muchas son las ramificaciones del «derecho a la salud» examinadas en la jurisprudencia del TEDH. Destacaremos solamente dos:

a) en materia de expulsión de extranjeros: La Sentencia de Gran Sala de 13 de Diciembre de 2016, Paposhvili c. Bélgica, considera vulnerados los artículos 3 y 8 del Convenio (prohibición de los malos tratos y del derecho a la vida familiar, respectivamente), en caso de expulsión a su país de origen, Georgia, de una persona que sufre graves enfermedades (tuberculosis, hepatitis $C$ y leucemia linfática crónica, donde no existía la certeza de poder contar con un tratamiento médico apropiado. Las demandas de asilo y de regularización en Bélgica del demandante y su esposa habían sido previamente rechazadas. El Tribunal aplicó una medida cautelar para impedir que el demandante fuera expulsado de Bélgica durante la tramitación de su demanda ante el TEDH ${ }^{22}$. El 29 de Julio de 2010, la esposa del demandante obtuvo, para ella y sus tres hijos, un permiso de residencia ilimitado. El demandante falleció en Junio de 2016 (aunque el examen del caso prosiguió, ya que el Tribunal consideró que el respeto de los derechos humanos garantizados por el Convenio y sus Protocolos así lo exigían, según el artículo $37 \S 1$ in fine del Convenio). En cuanto al fondo del asunto, el TEDH estimó que la falta de tratamientos adecuados en el país de destino, o de acceso a los mismos, incluso en ausencia de riesgo de muerte inminente, sometería al enfermo a un riesgo real de ser expuesto a un empeoramiento grave, rápido e irreversible de su estado de salud, implicando sufrimientos intensos o una reducción significativa de su esperanza de vida. Tal riesgo correspondería exponerlo al demandante ante el Tribunal. Si tal fuera el caso, incumbiría entonces al Estado que ha previsto la expulsión disipar las dudas al respecto y, si éstas persisten, obtener la seguridad del Estado de destino de que la persona en cuestión recibirá los tratamientos necesarios. La ausencia de esta evaluación por parte de las autoridades belgas hizo concluir al Tribunal que seguir adelante con la expulsión expondría al demandante a un trato contrario al artículo 3. La falta de examen por parte de dichas autoridades del grado de dependencia de su familia derivado de la degradación del estado de salud del demandante y de la cuestión de saber si su familia podía razonablemente seguirle a Georgia o si, en caso contrario, el respecto de su vida familiar exigía que se le autorizara a residir junto a ellos en Bélgica durante el tiempo que le quedara de vida hizo al Tribunal concluir que se había vulnerado el artículo 8.

22 Ver también Sentencia de Gran Sala de 27 de Mayo de 2008 dictada en el caso N. c. Reino Unido. (n. $\left.{ }^{\circ} 26565 / 05\right)$. 
b) en situaciones de privación de libertad: La Sentencia de 13 de Marzo de 2018 dictada en el caso Ebedin Abi c. Turquía concluyó que se había vulnerado el artículo 3 del Convenio por el régimen alimentario del demandante durante su detención. El demandante se quejaba de no tener acceso a un régimen alimentario conforme con lo prescrito médicamente para sus enfermedades (régimen apto para diabético, hipocalórico y pobre en carne de ternera y en grasas saturadas) y de la deterioración de su salud por esta razón. El Tribunal consideró que las autoridades internas no adoptaron las medidas necesarias para la protección de la salud y bienestar del demandante y que no le garantizaron unas condiciones de detención adecuadas y respetuosas con la dignidad humana.

La Sentencia Boukrourou y otros c. Francia, de 16 de Noviembre de 2017, examina el caso de una persona con problemas psiquiátricos que sufrió malos tratos durante una intervención policial. El Tribunal concluyó que se había vulnerado el artículo 3 porque el trato infligido al demandante - gestos violentos, repetidos e ineficaces, practicados sobre una persona vulnerable - atenta contra la dignidad humana y supone un nivel de gravedad que lo hace incompatible con dicha disposición del Convenio. En este sentido merece la pena destacar también la Sentencia de 18 de Diciembre de 2007 dictada en el caso Dybeku c. Albania, en la que el Tribunal exige, conforme al artículo 46 del Convenio, medidas generales al Estado demandando de mejora urgente de las condiciones de detención, y condiciones de detención satisfactorias y cuidados médicos adecuados para detenidos que precisen un trato particular por su estado de salud. En el caso concreto se trataba de un detenido que padecía esquizofrenia paranoica crónica, y su estado psicológico le hacía más vulnerable, habiendo podido su detención exacerbar sus sentimientos de tristeza, angustia y miedo. En todo caso, según entiende el Tribunal, la falta de recursos no puede en principio justificar condiciones de detención lamentables que alcanzan el nivel de gravedad susceptible de vulnerar el artículo 3. Para ello tiene además en cuenta las conclusiones de los informes del Comité de prevención de la torture du Consejo de Europa (CPT) sobre las condiciones de detención en las prisiones albanesas, particularmente en cuanto a detenidos con enfermedades mentales. Por ello entiende el TEDH que la naturaleza, la duración y la gravedad de los malos tratos sufridos por el demandante y los efectos negativos acumulados que éstos han producido en su salud son suficientes para calificarlos de tratos inhumanos y degradantes.

\section{CONCLUSIONES}

A pesar de la no inclusión, salvo excepción, de los derechos económicos y sociales en el Convenio, el Tribunal no ha escatimado medios en su interpretación favorable a la acogida de los mismos en su jurisprudencia, sirviéndose para ello de la protección indirecta para salvar la ausencia de mención expresa a esos derechos mediante la conexión con otros que sí están expresamente consagrados en dicho texto. A este respecto debe añadirse el recurso que el Tribunal hace a la Carta Social Europea en sus Sentencias, pero también a otros textos e instrumentos internacionales y, en particular a textos adoptados en el seno del Consejo de Europa como, por ejemplo, el Convenio contra la trata de seres humanos 
o los informes del Comité Europeo para la prevención de la tortura y los tratos y penas inhumanos y degradantes a los que ya se ha hecho referencia.

Se observa, a la vista de las líneas que preceden, que la jurisprudencia del Tribunal otorga en general un amplio margen de apreciación a los Estados en cuanto a las puesta en práctica de políticas sociales y económicas. Por otra parte, como ya se apuntó, para concluir que se ha vulnerado algún derecho sustantivo en situaciones de pobreza extrema o de dureza de las condiciones de subsistencia, el Tribunal es muy estricto y analiza las situaciones de manera individualizada y estricta, aplicando plenamente el principio de subsidiariedad que informa todo el sistema del Convenio, sin extraer consecuencias de carácter general sobre las políticas económicas aplicadas.

Combinando todos estos aspectos y ante las situaciones que el Tribunal está llamado a examinar, sus Sentencias contribuyen a la emergencia y consolidación de una verdadera jurisprudencia sobre los derechos económicos y sociales en el marco del Convenio Europeo de Derechos Humanos, dándoles plena justiciabilidad y carácter obligatorio y vinculante de los que en principio carecían.

TITLE: Economic and social rights in the recent case-law of the european court of human rights: a selection

ABSTRACT: The European Court of Human Rights and its case law have faced several situations and issued many judgments over the years stating that the Convention imposes obligations on the States in an economic and social context and/or indirectly protecting these rights, which the Court has examined via a broad, dynamic and evolutive interpretation..

Resumen: El Tribunal Europeo de Derechos Humanos y su jurisprudencia han analizado diversas situaciones y dictado numerosas sentencias a lo largo de los años estableciendo que el convenio impone obligaciones positivas a los Estados en el contexto de los derechos económicos y sociales y/o protegiendo indirectamente estos derechos indirectamente, mediante la interpretación abierta, dinámica y evolutiva del Tribunal.

KEY WORDS: economic and social rights, positive obligations, social benefits, economic crisis, dismissal, housing, education, bealth, European Court of Human Rights.

PALABRAS CLAVE: derechos económicos y sociales, obligaciones positivas, prestaciones sociales, crisis económica, despido, vivienda, educación, salud, Tribunal Europeo de Derechos Humanos.

FECHA DE RECEPCIÓN: 29.06.2018

FECHA DE ACEPTACión: 13.09.2018 